and supervisors were all cleared of misconduct in the final report, they could have been more curious about his results. Similarly, when Schön applied for patents, he was not required to show or have others sign his laboratory notebook his use of which is questionable.

It must also be noted that an accusation of misconduct is not a finding. And an incorrect or false accusation can ruin reputations or destroy careers, even if the accusation is later recognized as wrong. This puts a burden on institutions that requires thought and investigation before public disclosure, which slows the process.

Reich opines that the memory of this particular affair will fade. But the possibility of scientific misconduct cannot be eradicated. Many people are involved in educating scientists at all stages of their careers to keep the possibility of scientific fraud, plagiarism, conflict of interest and other unethical behaviour before them. For example, at a 2003 workshop that I convened in London, more than 70 international participants, including publishers, editors and working scientists, discussed aspects of unethical behaviour, as well as the Schön affair. The result was a set of guidelines that was adopted, after minor modification, by the council of the International Union of Pure and Applied Physics (see http:// tinyurl.com/iupap-ethics).

Scientific associations, such as the American Physical Society (APS) and the Council of Science Editors, have developed and updated codes of behaviour and educational programmes before and since this landmark case. The APS policy (http://tinyurl.com/aps-policy) includes a report on ethics education, which is vital to define and promote ethical behaviour by all scientists. Reich herself references the Beasley report using a link on the website of the APS. I was responsible for posting it there, with permission from Bell Labs' owners Lucent Technologies, following the retraction of six articles co-authored by Schön in the APS journals for which I was then editor-in-chief. It is fortunate that this stable link keeps the report accessible years later (see http://publish.aps.org/reports).

The prevention and uncovering of scientific misconduct requires vigilance, education and humility on the part of scientists, managers, editors, journals and journalists to maximize the probability of correction. In the Schön affair, several of these elements combined to raise that probability enough so that correction occurred. It is unfortunate that Reich did not draw fairer conclusions, despite her hard work in reporting the facts.

Martin Blume is editor-in-chief emeritus at the American Physical Society and senior physicist emeritus at Brookhaven National Laboratory, Upton, New York, USA.

e-mail: blume@post.harvard.edu

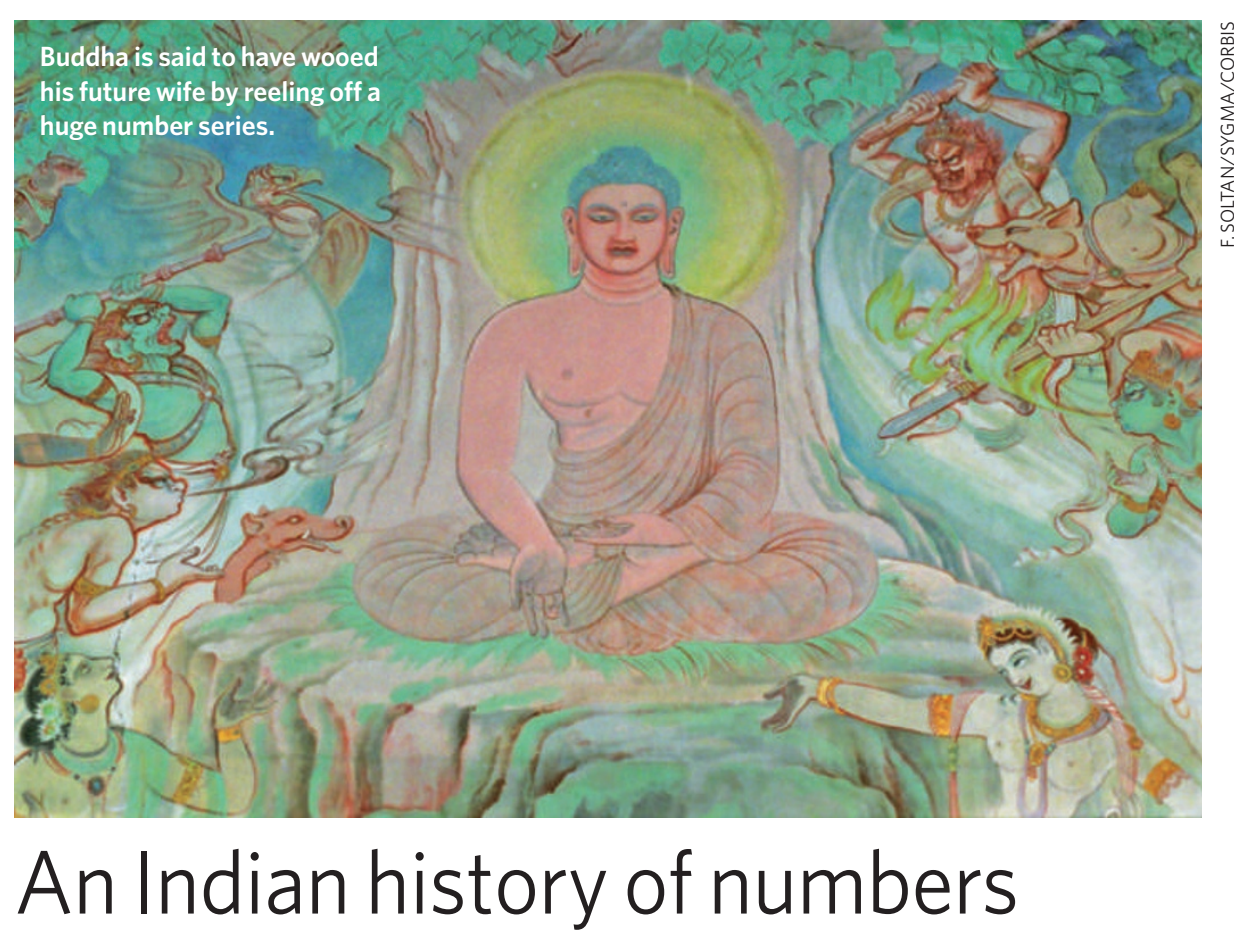

In a world divided by culture, politics, religion and race, it is a relief to know one thing that stands above them - mathematics. The diversity among today's mathematicians shows that it scarcely matters who invents concepts or proves theorems; cold logic is immune to prejudice, whim and historical accident. And yet, throughout history, different families of humans have distilled the essence of the cosmos to capture the magic of numbers in many ways.

Mathematics in India shows just how different one of these ways was, and how culture and mathematical development are intimately connected. This carefully researched chronicle of the principal contributions made by a great civiliza-

Mathematics In India
by Kim Plofker
Princeton University Press: 2009.
394 pp. $€ 28.95$

sciences. Another reason is that many ancient Indian mathematical texts have long been extinct; often, the only indication that they existed comes from scholars who refer to the work of their predecessors. As Plofker wryly notes, two historians of Indian maths recently published articles in the same edited volume, wherein the estimates of their subject's origins differed by about 2,000 years.

Still, surviving Sanskrit texts reveal a rich tradition of Indian mathematical discoveries lasting more than 2,500 years. In the Early Vedic period (1200-600 вC), a decimal system of numbers was already established in India, together with rules for arithmetical operations (ganita) and geometry tion covers the earliest days of Indian history through to the beginning of the modern period. Regrettably, it stops short of the legendary mathematician Srinivasa Ramanujan (born 1887), whose name is still seen in today's research papers.

Kim Plofker's book fulfils an important need in a world where mathematical historiography has been shaped by the dominance of the Greco-Christian view and the Enlightenment period. Too little has been written on the mathematical contributions of other cultures. One reason for the neglect of Indian mathematics was Eurocentrism - British colonial historians paid it little attention, assuming that Indians had been too preoccupied with spiritual matters to make significant contributions to the exact (rekha-ganita). These were encoded in a complex system of chants, prayers, hymns, curses, charms and other religious rituals. Cryptic phrases called sutras contained arithmetical rules for activities such as laying out a temple or arranging a sequence of sacrificial fires.

Large numbers held immense fascination. Acclamations of praise to the air, sky, times of day or heavenly bodies were expressed in powers of ten that went to a trillion or more. Reputedly, the young Prince Buddha successfully competed for the hand of Princess Gopa by reciting a number table that included names for the powers of ten beyond the twentieth decimal place.

As in other early agricultural civilizations, Indian mathematics probably emerged in 
response to the need to measure land areas and keep track of financial transactions, incomes and taxation. A rigid caste and class hierarchy reserved the mystery of numbers for elite Brahmins. To maintain personal power, mathematical knowledge was jealously guarded. Its communication was deliberately made difficult, such as in the perplexing rhythmic chant of mathematician Aryabhatta in the fifth century AD: "makhi-bhakhi-phakhidhaki-nakhi-nakhi-nakhi-hasjha-skaki-kisgasghaki-kighva-ghaki..." This recital of values of sine differences in arc minutes would be memorized by aspiring mathematicians in much the same way as verses of the sacred text Bhagavadgita.

The book details the impressive achievements of Indian mathematicians, from Aryabhatta through Brahmagupta, Mahavira, Bhaskara and Madhava, until the Sanskrit tradition became irrelevant with the invasion of modern mathematics from Europe in the nineteenth century. Major discoveries include finding the solution to indeterminate equations and the development of infinite series for trigonometric quantities. Discovered in the fourteenth century by the Kerala school founded by Madhava, these series built on the work of Bhaskara II and grew from the ingenious computation of a circle's circumference. By breaking up the circle into polygons, Madhava was able to calculate the value of pi correct to 11 decimal places. Some developments preceded those in Europe. For example, Reuben Burrow - a British mathematician posted to Bengal as an instructor in the engineers corps - was intrigued by rules he discovered in an unnamed Sanskrit text, and wrote a paper in 1790 entitled 'A Proof that the Hindoos had the Binomial Theorem'.

But how peculiarly Indian was early Indian mathematics? Did it evolve in isolation or did it absorb ideas and knowledge from elsewhere? Cultural pride in their recently reinvigorated country causes some Indians to claim that all worthwhile mathematics originated in ancient India. But this book will not please them. Plofker is not ready to certify that the concept of zero was an Indian invention; it could well have been conveyed by Chinese Buddhist pilgrims. Nor is she willing to believe that differential and integral calculus were anticipated in India ahead of the work of Gottfried Leibniz and Isaac Newton.

The chapter entitled 'Exchanges with the Islamic World' is of particular significance. The Muslim conquest of India brought with it the Islamic mathematical tradition, which was founded on Greek mathematics. Muslims made important advances in maths between the ninth and thirteenth centuries. Greco-Islamic and Indian mathematics were structured quite differently, with the former emphasizing proof and the latter, result. Probably because of Islamic influence, Indian ideas on the nature of mathematical proof moved in the direction of greater rigour.

The book carefully separates fact from hyperbole, copiously quoting formulae. This makes for heavy reading in places, and one wishes that it had been interspersed with vignettes and light anecdotes. It is more of a research monograph than a popular book. But that is the price that scholarship exacts.

Mathematics in India explains how the early development of Indian maths was influenced by religion, by the need to build temples of specific proportions and to meet astrological imperatives. Similarly, it could be argued that Islamic mathematics was religiously motivated - for example, by the need to know the precise times of daily prayers, and to determine the direction of the holy Kaaba (the Qibla). But a quadratic equation solved by whoever, by whatever means and for whatever purpose must give exactly the same solutions. Ultimately, mathematics is mathematics. Pervez Hoodbhoy is professor of physics at Quaid-e-Azam University, Islamabad, Pakistan. e-mail: pervez.hoodbhoy@gmail.com

\section{Averting environmental crisis}

One of the most important questions of our age is when will humankind take action to offset the impact of climate change? Will we do something before the inexorable rise in sea level or wait until the effect is cataclysmic? Can the history of previous environmental crises help us to predict the course of this one?

Two books address these challenges. In the first, Becoming Good Ancestors, David Ehrenfeld, a zoologist and the founding editor of the journal Conservation Biology, examines the destructive tendencies of humankind. He asks if we can "move ourselves and our society toward a more stable, less frantic, more responsible, and far more satisfying life". The book is an expanded and revised collection of some three dozen essays that Ehrenfeld published first in Orion magazine and then in Swimming Lessons: Keeping Afloat in the Age of Technology (Oxford University Press, 2002). The result is a very good read.

Ehrenfeld believes that we must jettison our arrogant assumption of being able to fix anything through technology, that we forget at our peril what worked well in the past and that economics is a cloudy lens through which to view human behaviour. He says that we must and can reconnect with a nature that is resilient and that, despite globalization, local communities will never completely disappear. The essays retain the qualities that made them appealing when they were first published brevity, passion and accessibility. However, as satisfying as they are as self-contained meditations, they do not hang together well, either as a sequence or as a complete analysis.
Nature and Power is a very different work, written by an environmental historian who refuses to follow convention unless he finds compelling reason to do so. Joachim Radkau's vision in this broad-reaching history of the state of the environment - in particular, its soils, forests and waters - is from three perspectives, namely German, continental European and global. His unrelenting focus on detail may frustrate the reader who seeks straightforward narrative. Many writers can be said to miss the forest for the trees, but Radkau is extreme, at times abandoning the tree for the twig, bud, leaf or abscission scar.

Radkau's guiding lights are demographer Thomas Malthus, sociologist Max Weber and the nineteenth-century agricultural chemist Justus von Liebig. Radkau draws on von Liebig in his discussions on the chemistry, well-being and degradation of soils; on Weber in his acknowledgement of the crucial role of culture and power in the course of environmental history; and on Malthus for his case that population pressure on resources is the enemy of sustainability. Radkau doesn't just apply these and many other ideas, but tests, refines and refutes them in chapters that range through time and across the globe. The book often startles. Insights come thick and fast with Radkau's ironic and unexpected turns of phrase.

True to form, he refuses to take the easy route. He comes close to declaring that environmental history is mostly about decline, and that human population control is the key to reducing resource pressure, yet he pulls back from whatever precipice he is nearing 